\title{
Receptor for activated C-kinase (RACK1) plays a central role in Ras-mediated signal transduction
}

\author{
Johan R Lillehaug ${ }^{*}$, Line M Myklebust, Arnt Raae, Bodil Bjørndal \\ From 16th International Charles Heidelberger Symposium on Cancer Research \\ Coimbra, Portugal. 26-28 September 2010
}

Receptor for activated C-kinase 1 (RACK1) is involved in a multitude of cellular actions regulating cell development, growth, movement, and apoptosis. RACK1 is an important scaffolding protein active in several different signaling pathways. RACK1 has recently been linked to tumor growth, found to be up-regulated in breast, melanoma, lung, colon, and oral squamous cancers.

Activating Ras mutations are involved in a significant fraction of human tumors. A suppressor screen using a retroviral mouse fibroblast cDNA library was performed to identify novel factors in Ras-mediated transformation. We identified a potent inhibitor of Ras-mediated morphological transformation encoded by a truncated version of the receptor for activated C-kinase (RACK1) [1]. The truncated protein, designated RACK1 $\triangle \mathrm{WD} 1$, lacked the N-terminal 49 amino acids encoding the first of the seven WD40 repeats in RACK1. RACK1 $\triangle W D 1$ expression restored contact inhibition, stress fiber formation, and reduced ERK phosphorylation in Ki-Ras transformed NIH 3T3 cells. We demonstrate that truncated RACK1 is involved in complexes consisting of wild-type RACK 1 and protein kinase $C$ isoforms $\alpha, \mathrm{I}$, and $\delta$, compromising the transduction of an activated Ras signal to the Raf-MEK-ERK pathway. Notably, 12-O-tetradecanoyl-13-phorbol acetate (TPA) mediated intracellular translocation of RACK1-interacting PKC $\alpha$ and $\delta$ was abrogated in RACK1 $\triangle \mathrm{WD} 1$-expressing cells. Our data support a model where RACK1 acts as a key factor in Ki-Ras-mediated morphological transformation. By use of co-immunoprecipitation and co-localization analysis in mammalian cells, we found RACK1 to exist in a complex with Ki-Ras and B-Raf. In cells expressing both RACK1and a RACK1 mutant, RACK1 $\triangle \mathrm{WD} 1$, the mutant protein was also present in this complex. Surface Plasmon resonance (SPR) technology analysis confirmed these interactions in vitro and explained the selective binding of RACK1-Ki-Ras-GTP relative to RACK1-Ki-Ras-GDP with a 10-fold increase in the binding strength and further proved the mutant Ki-Ras (G12C) to increase this interaction 16-fold. Interestingly, RACK1 $\triangle W D 1$ bound significantly stronger to Ki-RasGTP than RACK1 presenting a 5-fold increase in the equilibrium dissociation constant. This confirms that RACK1 $\triangle W D 1$ may function as a competitor of RACK1 interactions. SPR experiments demonstrated that B-Raf binds to Ki-Ras forming a complex with RACK1. Therefore, our present findings establish a direct physical involvement of RACK1 as a scaffold protein in regulating the Ras-Raf-Mek-Erk signaling cascade essential in cancer development.

RACK1 mRNA and protein expression in papillary thyroid carcinomas were studied using RT-PCR and immunohistochemistry respectively. Both at the mRNA and protein level, RACK1 was found to be highly expressed in all tumour cells while Ki-Ras was found to be unchanged and B-Raf barely detectable. Sequencing analysis detected no mutations in RACK1 or Ki-Ras, but $60 \%$ of the patients presented the B-Raf single nucleotide substitution T1799A (codon V600E) which is reported frequently in thyroid cancers.

Our studies places RACK1 as an important regulator of Ras-mediated signal transduction forming "communi-

\footnotetext{
* Correspondence: johan.lillehaug@mbi.uib.no

Department of Molecular Biology University of Bergen, Bergen, Norway

Full list of author information is available at the end of the article
} 
cation-hub" consisting of activated Ras-Raf-PKCRACK1. RACK1expression is significantly upregulated in thyroid papillary carcinomas and a mutated form of RACK1 negatively interferes with Ras signalling.

Published: 24 September 2010

\section{Reference}

1. Bjørndal B, Myklebust LM, Rosendal KR, Myromslien FD, Lorens JB, Nolan G, Bruland O, Lillehaug JR: RACK1 regulates Ki-Ras-mediated signaling and morphological transformation of 3T3 cells. Int J Cancer 2007, 120:961-969.

doi:10.1002/ijc.22373

Cite this article as: Lillehaug et al.: Receptor for activated C-kinase

(RACK1) plays a central role in Ras-mediated signal transduction. BMC

Proceedings 2010 4(Suppl 2):010.

Submit your next manuscript to BioMed Central and take full advantage of:

- Convenient online submission

- Thorough peer review

- No space constraints or color figure charges

- Immediate publication on acceptance

- Inclusion in PubMed, CAS, Scopus and Google Scholar

- Research which is freely available for redistribution

Submit your manuscript at www.biomedcentral.com/submit 